\title{
Online Medical Education during COVID-19 Pandemic
}

\section{Sharma P}

Coronavirus disease (COVID-19) is an infectious disease caused by a newly discovered coronavirus. COVID-19 was declared a global pandemic on 12th March 2020.

Since it was a novel coronavirus infection, everything related to it or consequences of its infection was new and challenging to the mankind. Prevention strategies taken by governments across the world were lockdown, social distancing, closure of universities, schools, etc. On 24th March 2020, the Government of Nepal also imposed a nationwide lockdown. There was then an uncertainty on how long the lockdown would continue.

This way, COVID-19 had an impact on medical education globally leading to cancellation of lectures, clinical postings and exams. The medical course is vast and there is always a pressure to complete it within an academic year. The only solution to release this pressure was to go online as other countries did. The universities soon instructed their affiliate medical colleges to start online classes from midApril 2020. With short technical briefing to the students and teachers, the medical institutions started online classes to the students. Then the students who were habituated to traditional lectures had a sudden shift to online classes through the video communications application like Zoom, Microsoft team, etc. With the start of virtual lectures, the students were losing direct face to face contact and interaction with their teachers. The direct face to face interactive session during lectures is actually considered to be a crucial part of active learning.

Although we are used to referring online resources for learning, this novel approach incorporated for medical teaching was a new beginning for all of us. The prompt implementation of online classes has led to a very new experience among the students and the teachers alike. According to a recent survey, more than three-fourths of the students responded to have never attended online classes before the COVID-19 pandemic.

Basic know how of the digital technology in students and the teachers is an essential part of online teaching learning and it is very challenging for a resource poor setting like ours. In our setting, only $56 \%$ of the total population have access to internet. ${ }^{1}$ The poor network coverage in the rural region of the country is a hindrance for online medical education to be effective. Poor audio or video quality are important issues that disturb the classes often. Frequent power cuts leading to interruption further add to the problem in online classes. Online classes also impose extra financial burden to the medical students. The provision of discounted internet to access online learning for all the students would ease the financial burden of expensive internet.

Clinical teachings at bedside, laboratory skills, and community field learning are not possible with the online teaching format. But we should encourage our students to use the online resources as much as possible during this period of crisis. We should continually work up to make the online classes interesting and more effective, otherwise the students will soon lose their interest and cannot be a lifelong learner.

Although continuing medical education is a big challenge at this time of crisis, we have learnt to cope up with the situation with innovative teaching technology. Online class has become a solution during this period of crisis. We can refine our teaching techniques further to make the online teaching learning more interactive and effective. The students should also realize that they also have a great role to make the online classes more effective However, online lectures and video conferencing to demonstrate medical and surgical techniques will always remain as an open option even after the pandemic wanes off.

\section{REFERENCE:}

1. UNESCO. COVID-19: Impact on Education. UNESCO. 2020. Available from: https:// en.unesco.org/covid19/educationresponse [Accessed: 3rd December 2020] 